\title{
Economic Analysis of a Pumped Storage Project for Iran Generating System Based on a Dynamic Modeling
}

\author{
A.R. Sohrabi \\ Tavanir Co.Iran \\ Received: March 10, 2019. Revised: April 18, 2021. Accepted: September 20, 2021. Published: November 15, 2021.
}

\begin{abstract}
This paper proposes a dynamic model for evaluation of a Pumped Storage Project (PSP) . The optimal expansion policy is determined by considering different alternatives (Types of units: Rodbar PSP(RPSP), Steam Turbine, 2 types of Gas Turbine and a Combined Cycle) . Based on this model dynamic assessment of different alternatives (over a 20 years period and with a target Loss of Load Probability (LOLP)) provides economic $\begin{array}{lll}\text { justification } & \text { for }\end{array}$
\end{abstract}

Key words : Pumped Storage - Generating System Economic Analysis

\section{INTRODUCTION}

A new Dam construction Program in Rodbar-eLorestan area raised a series of questions: mainly is there an economic justification for construction of a PSP in The mentioned area ? If the answer is positive then what capacity is an optimal choice,...?

Two types of assessment is carried out:

1. Dynamic assessment, 2. Static assessment .

In this paper only results of dynamic assessment is presented. Dynamic programming has many advantages over the enumeration scheme, the chief advantage being reduction in the dimensionality of the problem [1] .In dynamic assessment, PSP is evaluated accounting for total generating system. Then it is necessary to determine not only PSP and other candidate units parameters but also parameters of other units within the total generating system. On the other hand an accurate load forecasting for study period (20 years) must be done and necessary constraints as LOLP rate, fuel limitations(natural gas) for thermal units in cold season, limitations on dams seasonal energy, and so on also are taken in to consideration .

Three different categories of units are considered in this assessment : existing, under construction and finally candidate units .

Only candidate units based on optimal procedure will be selected (in type and quantity) by model , excluding RPSP that is unique in each case .
There is no other hydroelectric alternative candidate (Excluding RPSP) this is because these types of units are not selectable as unlimited numbers and existences of these units depend on topology of country and each one must be evaluated separately ( like RPSP) .

Nine cases are generated for 9 steps of RPSP capacity $(0,250,500, \ldots, 2000 \mathrm{Mw})$ it is because as a final assessment we need also to determine optimal RPSP capacity .

As mentioned before other selectable candidates are defined for model as below:

1. Steam Turbine $325 \mathrm{Mw}, 2$. Base Gas Turbine $130 \mathrm{Mw}, 3$. Peak Gas Turbine $130 \mathrm{Mw}$, 4. Combined Cycle 400Mw .

\section{INPUT DATA PREPARATION}

The dynamic modeling is performed by using WASP IV (Wien Automatic System Planning )[2], This model consists of six following main modules :

Loadsy - Fixsys -Varsys - Congen - Mersim - Dynpro (Dynamic Programming optimization )

In fact dynamic programming finally performed by last module and almost others act as input data preparation for this block .

In this section all necessary data, mathematical relations and a brief descriptions of calculation procedure is presented in short .

In first step based on the historical load data, peak load values are forecasted for the period of time under study.It is also assumed that Load Duration Curves (LDCs) have the same shape for similar seasons .

A sample of Normalized Load Duration Curve (NLDC) with 31 points for each season is shown in Table 1 . Model uses a fourier approximation for LDC to calculate necessary energy of system in each period .In next step data for fixed generating system consisting of existing, under construction and also for candidate units are determined. 
Table .1 : Sample of NLDC points for Year 2004 period 2: Summer (part of data)

\begin{tabular}{|c|c|c||}
\hline NO & Load & Duration \\
\hline 1 & 1.0000 & 0.0000 \\
\hline 2 & 0.9851 & 0.0077 \\
\hline 3 & 0.9701 & 0.0158 \\
\hline 1 & 1 & 1 \\
\hline 1 & 1 & 1 \\
\hline 1 & 1 & 0.9181 \\
\hline 26 & 0.6266 & 0.9410 \\
\hline 27 & 0.6117 & 0.9594 \\
\hline 28 & 0.5967 & 0.9747 \\
\hline 29 & 0.5818 & 0.9881 \\
\hline 30 & 0.5668 & 1.0000 \\
\hline 31 & 0.5519 & \\
\hline
\end{tabular}

The data depending on unit type have a wide variety, for example :

Power capacity, Fixed and variable operating and maintenance cost are determined based on Ref [3].

Force Outage Rate (FOR) is calculated based on Ref[4].

Base Load Heat Rate (BLHR) (or Heat rate at minimum operating level) for thermal units can be driven based on following formula:

$$
\mathrm{BLHR}=\frac{859.8}{\boldsymbol{e}_{1}}[\mathrm{kcal} / \mathrm{kwh}]
$$

And for Full Load Heat Rate ( FLHR) we have :

$$
\text { FLHR }=\frac{859.8}{e_{2}}[\mathrm{kcal} / \mathrm{kwh}]
$$

Then Average Incremental Heat Rate (AIHR) can be calculated as below :

$$
\mathrm{AIHR}=\frac{F L H R^{*} P_{\text {full }}-B L H R^{*} P_{\text {base }}}{P_{\text {full }}-P_{\text {base }}}
$$

Where $e_{1}, e_{2}, P_{\text {base }}, P_{\text {full }}$ respectively are unit efficiencies and power capacities at minimum and maximum operating levels .

See Table. 2 for existing and Table. 3 for candidate units' data.
Table .2

Sample of existing units main data

\begin{tabular}{||l|c||}
\hline No & 1 \\
\hline Power Plant Name & Tabs \\
\hline Type & ST \\
\hline Number of Units & 2 \\
\hline MOL[Mw] & 225 \\
\hline MGC[Mw] & 300 \\
\hline Fuel Type & 3 \\
\hline BLHR[kcal/kwh] & 2235 \\
\hline AIHR[kcal/kwh] & 2271 \\
\hline FOR[\%] & 17.1 \\
\hline SM[ Days/Year] & 59 \\
\hline FFC[C/million kcals] & 546 \\
\hline FOMC[\$/kw-month] & 0.125 \\
\hline VOMC[\$/Mwh] & 0.213 \\
\hline
\end{tabular}

Table .3

Candidate units main data

\begin{tabular}{||l|c|c|c|c||}
\hline \hline No & 1 & 2 & 3 & 4 \\
\hline Candidate Name & S325 & G13P & G13B & CC40 \\
\hline Type & ST & GT & GT & CC \\
\hline MOL[Mw] & 163 & 0.1 & 65 & 200 \\
\hline MGC[Mw] & 325 & 130 & 130 & 400 \\
\hline Fuel Type & 3 & 4 & 4 & 4 \\
\hline BLHR[kcal/kwh] & 2330 & 2507 & 3140 & 1857 \\
\hline AIHR[kcal/kwh] & 2137 & 2507 & 1875 & 1583 \\
\hline FOR[\%] & 7.8 & 6.12 & 6.12 & 6.74 \\
\hline SM[ Days /Year] & 56 & 40 & 40 & 43 \\
\hline FFC[C/million kcals] & 546 & 621 & 621 & 621 \\
\hline FOMC[\$/kw-month] & 0.3034 & 0.0892 & 0.0892 & 0.1392 \\
\hline VOMC[\$/Mwh] & 0.3935 & 0.8773 & 0.8773 & 0.6134 \\
\hline DCC:1.Domestic[\$/Kw], & 230.3 & 137.7 & 137.7 & 198.8 \\
\cline { 2 - 6 } 2.Foreign[\$/Kw] & 501.2 & 200.2 & 200.2 & 316.2 \\
\hline IDCC [\%] & 19.21 & 15 & 15 & 30 \\
\hline Plant Life[years] & 30 & 15 & 15 & 30 \\
\hline CT[years] & 5 & 2 & 2 & 4 \\
\hline \hline
\end{tabular}

\begin{tabular}{|c|c|}
\hline Description & Fuel Type: \\
\hline Heavy Fuel Oil(HFO) & 1 \\
\hline Gas Oil & 2 \\
\hline $5+1$ & 3 \\
\hline $5+2$ & 4 \\
\hline Natural Gas(NG) & 5 \\
\hline
\end{tabular}

following abbreviations are used :

Min Operating Level (MOL),Max Generating Capacity (MGC) , Force Outage Rate (FOR) , Scheduled Maintenance (SM), Foreign Fuel Cost (FFC), Fixed O\&M Cost (FOMC), Variable O\&M Cost (VOMC), 
Depreciable Capital Cost (DCC),Interest During Construction included in capital Cost (IDCC) Construction Time(CT), Steam( ST), Gas Turbine(GT), Combined Cycle (CC)

DCC is divided in two parts : 1. Domestic DCC, 2. Foreign DCC.

Transmission line losses and Transfer costs for RPSP also are included in model .

Inflow energy is determined for hydro plants as seasonally. An annual target for LOLP equal 1 day per year is selected. For RPSP we have also following exclusive parameters :

Cycle efficiency, Pumping capacity and Max feasible energy[5] that are given in Table .4 .

Table .4

RPSP Data (part of data)

\begin{tabular}{||l|c|c|c|c|c||}
\hline MGC[Mw] & 250 & 500 & ---- & 1750 & 2000 \\
\hline FOMC[\$/kw-month] & 0.39 & 0.39 & ---- & 0.39 & 0.39 \\
\hline $\begin{array}{l}\text { Cycle Efficiency[\%] } \\
\text { Max.Feasible } \\
\text { energy[Gwh] }\end{array}$ & 80 & 80 & ---- & 80 & 80 \\
\hline $\begin{array}{l}\text { Plant Life[Years] } \\
\text { 2.Foreign [\$/Kw] }\end{array}$ & 118 & 237 & ----- & 958 & 1095 \\
\cline { 2 - 7 } & 50 & 50 & ---- & 50 & 50 \\
\hline $\begin{array}{l}\text { DCC: 1.Domestic[\$/Kw] } \\
\text { CT[years] }\end{array}$ & 229 & 237 & ----- & 256 & 271 \\
\hline \hline
\end{tabular}

\section{DYNAMIC MODELING}

Basically this dynamic model is designed to find economically optimal expansion policy for an electric utility system within user specified constrains . Model searches for the optimal scheme by using the forward dynamic programming algorithms. When some of the configuration schemes have been ruled out as infeasible with respect to reliability indices, model search for the minimum cost path in the rest of the schemes from the planning start year to the level year. Suppose that there are 100 feasible configuration schemes in the final year of planning. Model finds the minimum cost in the 100 minimum cost paths. The searching process is shown in Fig. 1 .

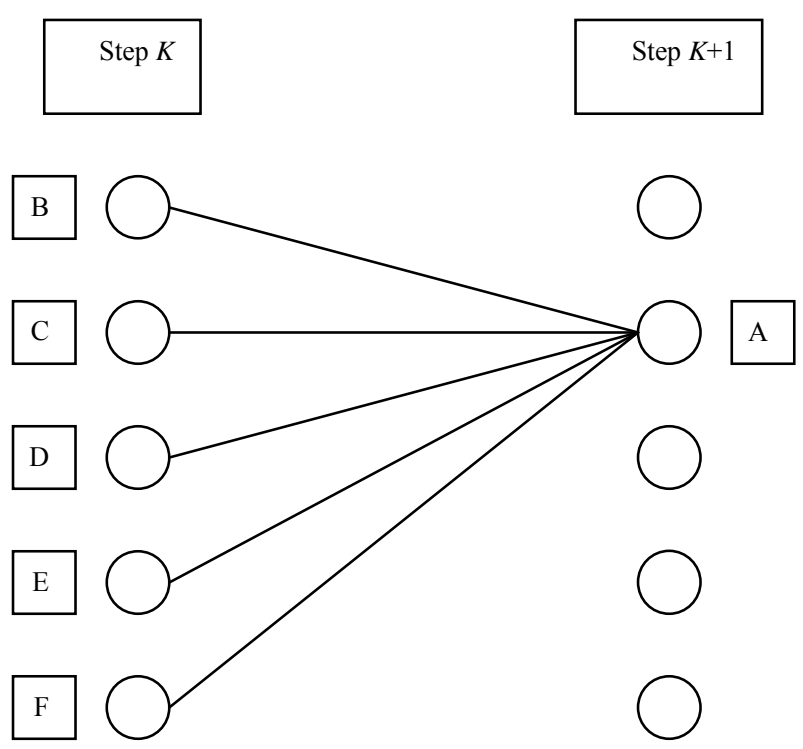

Fig.1 : Solution process of dynamic programming

Some of the feasible schemes in year $\mathrm{K}$ and year $\mathrm{k}+1$ are shown in this figure. The cost of every scheme is determined by the minimum cost path from the beginning to the end of the planning year. when calculating the cost from the feasible scheme B in year $\mathrm{k}$ to the feasible scheme $\mathrm{A}$ in year $\mathrm{k}+1$, discount conversion should be made on the investment from $\mathrm{B}$ to $\mathrm{A}$ and the operational cost of $\mathrm{A}$ and add on to the cost of B. The same method is used for the other schemes $\mathrm{C}, \mathrm{D}, \mathrm{E}, \mathrm{F}$ to $\mathrm{A}$. Thus the minimum cost path to scheme $\mathrm{A}$ is found and retained while the other paths to A are waived since the other paths cannot form the optimal scheme according to the basic principles of dynamic programming. When the same principle is applied to all the feasible schemes in the year $\mathrm{k}+1$ and the minimum cost path is found, the computation turns from the year $\mathrm{k}+1$ to the year $\mathrm{k}+2$. The optimal planning scheme is then the one with the minimum cost in all feasible schemes' minimum cost paths in the final planning year [6] .

Model utilizes probabilistic estimation of system production costs, un served energy cost, and reliability, linear programming technique for determining optimal dispatch policy satisfying exogenous constraints on environmental emissions, fuel availability and electricity generation by some plants, and the dynamic method of optimization for comparing the costs of alternative system expansion policies.

The first step in apply the dynamic programming method is to define the cost objective criteria[7]. Each possible sequence of power units added to the system (expansion plan or expansion policy) meeting the constraints is evaluated by means of a cost function (the objective function) which is composed of :

Capital investment costs (I), Salvage value of investment costs (S), Fuel costs (F), Fuel inventory costs (L), Non-fuel operation and maintenance costs 
(M), Cost of the energy not served (O) , The cost function to be evaluated by WASP can be represented by the following expression[2]:

$$
B_{j}=\sum_{t=1}^{T}\left[\overline{I_{j, t}}-\overline{S_{j, t}}+\overline{F_{j, t}}+\overline{L_{j, t}}+\overline{M_{j, t}}+\overline{O_{j, t}}\right]
$$

Where:

$\mathrm{Bj}$ is the objective function attached to the expansion plan $\mathrm{j}, \mathrm{t}$ is the time in years $(1,2, \ldots, \mathrm{T}), \mathrm{T}$ is the length of the study period (total number of years), and the bar over the symbols has the meaning of discounted values to a reference date at a given discount rate $\mathrm{i}$. The optimal expansion plan is defined by: Minimum $\mathrm{Bj}$ among all $\mathrm{j}[2]$.

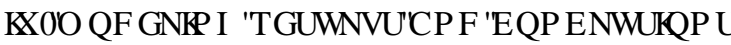

A dynamic method has been proposed which can be used to evaluate a PSP. Model is executed for 9 cases . This is because there are 9 steps for RPSP capacity . Results for case 8 (Capacity $1750 \mathrm{Mw}$ ) are given in Tables 5, 6 .

Table .5

Final results for case8 (RPSP Capacity $=1750 \mathrm{Mw}$ ) Part I

\begin{tabular}{||c|c|c|c|c|c|c||}
\hline Year & LOLP & ST & $\begin{array}{c}\text { Peak } \\
\text { GT }\end{array}$ & $\begin{array}{c}\text { CC } \\
\text { Base }\end{array}$ & $\begin{array}{c}\text { GT } \\
130\end{array}$ & $\begin{array}{c}\text { RPSP } \\
1750 \\
\text { MW }\end{array}$ \\
\hline 2023 & 0.27 & 0 & 271 & 171 & 0 & $1+$ \\
\hline 2022 & 0.27 & 0 & 234 & 154 & 0 & $1+$ \\
\hline 2021 & 0.26 & 0 & 213 & 134 & 0 & $1+$ \\
\hline 2020 & 0.27 & 0 & 178 & 120 & 0 & $1+$ \\
\hline 2019 & 0.26 & 0 & 130 & 112 & 0 & $1+$ \\
\hline 2018 & 0.27 & 0 & 104 & 100 & 0 & $1+$ \\
\hline 2017 & 0.27 & 0 & 99 & 81 & 0 & $1+$ \\
\hline 2016 & 0.26 & 0 & 96 & 64 & 0 & $1+$ \\
\hline 2015 & 0.27 & 0 & 90 & 48 & 0 & $1+$ \\
\hline 2014 & 0.27 & 0 & 50 & 42 & 0 & $1+$ \\
\hline 2013 & 0.26 & 0 & 32 & 32 & 0 & $1+$ \\
\hline 2012 & 0.27 & 0 & 23 & 20 & 0 & $1+$ \\
\hline 2011 & 0.26 & 0 & 13 & 9 & 0 & $1+$ \\
\hline 2010 & 0.26 & 0 & 9 & 5 & 0 & 0 \\
\hline 2009 & 0.11 & 0 & 0 & 0 & 0 & 0 \\
\hline 2008 & 0.02 & 0 & 0 & 0 & 0 & 0 \\
\hline 2007 & 0.01 & 0 & 0 & 0 & 0 & 0 \\
\hline 2006 & 3.87 & 0 & 0 & 0 & 0 & 0 \\
\hline 2005 & 6.73 & 0 & 0 & 0 & 0 & 0 \\
\hline 2004 & 8.23 & 0 & 0 & 0 & 0 & 0 \\
\hline
\end{tabular}

As shown in Table .5 , firstly (1+) means model is selected RPSP in first year of its availability ( 2011 ) and for achieving to a target LOLP ( 1 days per year = $0274 \%$ ) in an optimal expansion planning many units from two other candidates also are selected ( Peak Gas Turbine 13 and combined cycle 9 units in year 2011) and secondly $(1+)$ defines that not only this type of candidate is an economic unit but also model try to select more than one unit but remember that PSP is Unique in each one of cases .

Two other candidates ( Steam Turbine , Base Gas Turbine) are rejected by model .

In Table .6 cost main quantities are shown . Table.7 shows all cases Cumulative Costs for last year of study period (2023).

A comparison has been made between the 9 mentioned cases .With attention to Table.7 and also Fig. 2 it can be seen that without RPSP we have Maximum system Cumulative Cost and for capacity of $1750 \mathrm{Mw}$ system Cumulative Cost will be at the lowest level. That means this is optimal capacity for RPSP .

A sensitivity analysis on RPSP economic justification with respect to its DCC shows that RPSP $(1750 \mathrm{Mw})$ uneconomic behavior begins at DCC\# $520[\$ / \mathrm{Kw}]$.

Table .6

Final results for case8 (RPSP Capacity $=1750 \mathrm{Mw}$ ) Part II

\begin{tabular}{||c|c|c|c|c|c||}
\hline Year & $\begin{array}{c}\text { Construction } \\
\text { costs }\end{array}$ & $\begin{array}{c}\text { Operating } \\
\text { Costs }\end{array}$ & $\begin{array}{c}\text { ENS } \\
\text { Costs }\end{array}$ & $\begin{array}{c}\text { Total } \\
\text { Costs }\end{array}$ & $\begin{array}{c}\text { Cumulative } \\
\text { Costs }\end{array}$ \\
\hline 2023 & 838.4 & 1398.7 & 1.39 & 1487.0 & 43989.5 \\
\hline 2022 & 906.9 & 1431.9 & 1.03 & 1607.2 & 42502.4 \\
\hline 2021 & 874.8 & 1468.9 & 0.65 & 1719.6 & 40895.3 \\
\hline 2020 & 817.5 & 1497.7 & 0.33 & 1809.8 & 39175.7 \\
\hline 2019 & 865.2 & 1520.4 & 0.33 & 1894.9 & 37365.9 \\
\hline 2018 & 1088.5 & 1554.9 & 0.66 & 2064.8 & 35470.9 \\
\hline 2017 & 1052.6 & 1592.3 & 1.16 & 2141.8 & 33406.1 \\
\hline 2016 & 1134.2 & 1635.3 & 1.75 & 2290.3 & 31264.3 \\
\hline 2015 & 1049.1 & 1682.3 & 2.31 & 2415.6 & 28974.0 \\
\hline 2014 & 1099.1 & 1694.3 & 2.43 & 2460.7 & 26558.4 \\
\hline 2013 & 1216.0 & 1726.4 & 2.04 & 2593.9 & 24097.8 \\
\hline 2012 & 1262.0 & 1753.4 & 1.21 & 2702.3 & 21503.8 \\
\hline 2011 & 856.8 & 1781.7 & 1.03 & 2431.9 & 18801.6 \\
\hline 2010 & 804.6 & 1807.8 & 1.45 & 2479.7 & 16369.7 \\
\hline 2009 & 0.0 & 1838.3 & 0.73 & 1839.0 & 13890.0 \\
\hline 2008 & 0.0 & 1938.5 & 0.23 & 1938.7 & 12051.0 \\
\hline 2007 & 0.0 & 1972.7 & 0.14 & 1972.9 & 10112.3 \\
\hline 2006 & 0.0 & 1964.0 & 321.41 & 2285.4 & 8139.4 \\
\hline 2005 & 0.0 & 1952.0 & 809.03 & 2761.1 & 5854.0 \\
\hline 2004 & 0.0 & 1986.4 & 1106.55 & 3093.0 & 3093.0 \\
\hline \hline
\end{tabular}

Cost unit : Million US \$ 


\section{REFERENCES}

As secondary results these conclusions can be found in model output : Total consumption energy, Load factor, Peak and minimum load, Annual system generated energy based of fuel types and also by Hydro units ,Expected costs of operation \& maintenance and Energy Not Served (ENS) ,Capital cash flow summery of candidates .

Table .7

Cumulative System Costs for 9 steps of RPSP Capacity

\begin{tabular}{|c|c||}
\hline $\begin{array}{c}\text { RPSP } \\
\text { Capacity }[\mathrm{Mw}]\end{array}$ & $\begin{array}{c}\text { Cumulative System Cost for } \\
\text { Year 2023[MillionUS \$] }\end{array}$ \\
\hline 0 & 44046.0 \\
\hline 250 & 44031.6 \\
\hline 500 & 44025.5 \\
\hline 750 & 44007.8 \\
\hline 1000 & 44005.9 \\
\hline 1250 & 44003.4 \\
\hline 1500 & 43991.9 \\
\hline 1750 & 43989.5 \\
\hline 2000 & 43995.7 \\
\hline
\end{tabular}

\section{ACKNOWLEDGMENTS}

The authors gratefully acknowledge The IAEA planning and economic studies section for their useful suggestions .
[1] Allen J.Wood, Bruce F.Wollenberg ,Power Generation Operation \& Control, John Wiley \& Sons, 1996,p121

[2] Wien Automatic System Planning (WASP) Package, Version - IV User's Manual, International Atomic Energy Agency, 2000

[3] Economic information of Iran power plants, Tavanir production planning Dep , 2004

[4] IEEE Standard definition for use in Reporting Electric Generating Unit Reliability, Availability, and Productivity, ANSI/IEEE 762, 1987, p.15

[5] Technical report for Rodbar Pumped Storage Project, ghodsniroo Consulting engineer Co, 2005

[6] X.Wang , J.R.McDonald , Modern Power System Planning, McGraw-Hill Book Co., 1994, p.337

[7] Harry. G . Stoll, Least-Cost electric Utility Planning, john willy \& sons inc , 1989 , p516

\section{Creative Commons Attribution License 4.0 (Attribution 4.0 International, CC BY 4.0)}

This article is published under the terms of the Creative Commons Attribution License 4.0

https://creativecommons.org/licenses/by/4.0/deed.en_US

\section{BIOGRAPHY}

Alireza Sohrabi was born in Iran in 1966 , he received his B.Sc degree in Electrical Engineering (Power course ) from The Tehran University Faculty of Engineering in 1989. He joined Iran Ministry of Energy in 1991, at present he is as production planning engineer in Tavanir Co ( affiliated with Ministry of Energy ) .

His areas of interest are Power System Planning and Reliability analysis. The author can be contacted at:

VallyAsr St, Higher than Vanak Sq, Rashid Yasami St, Tavanir Blg 4 , production planning Dep ,Tehran, Iran , Tele: 0098-21-27935416,Fax: 0098-21-88644968 Email: sohrabi@Tavanir.org.ir

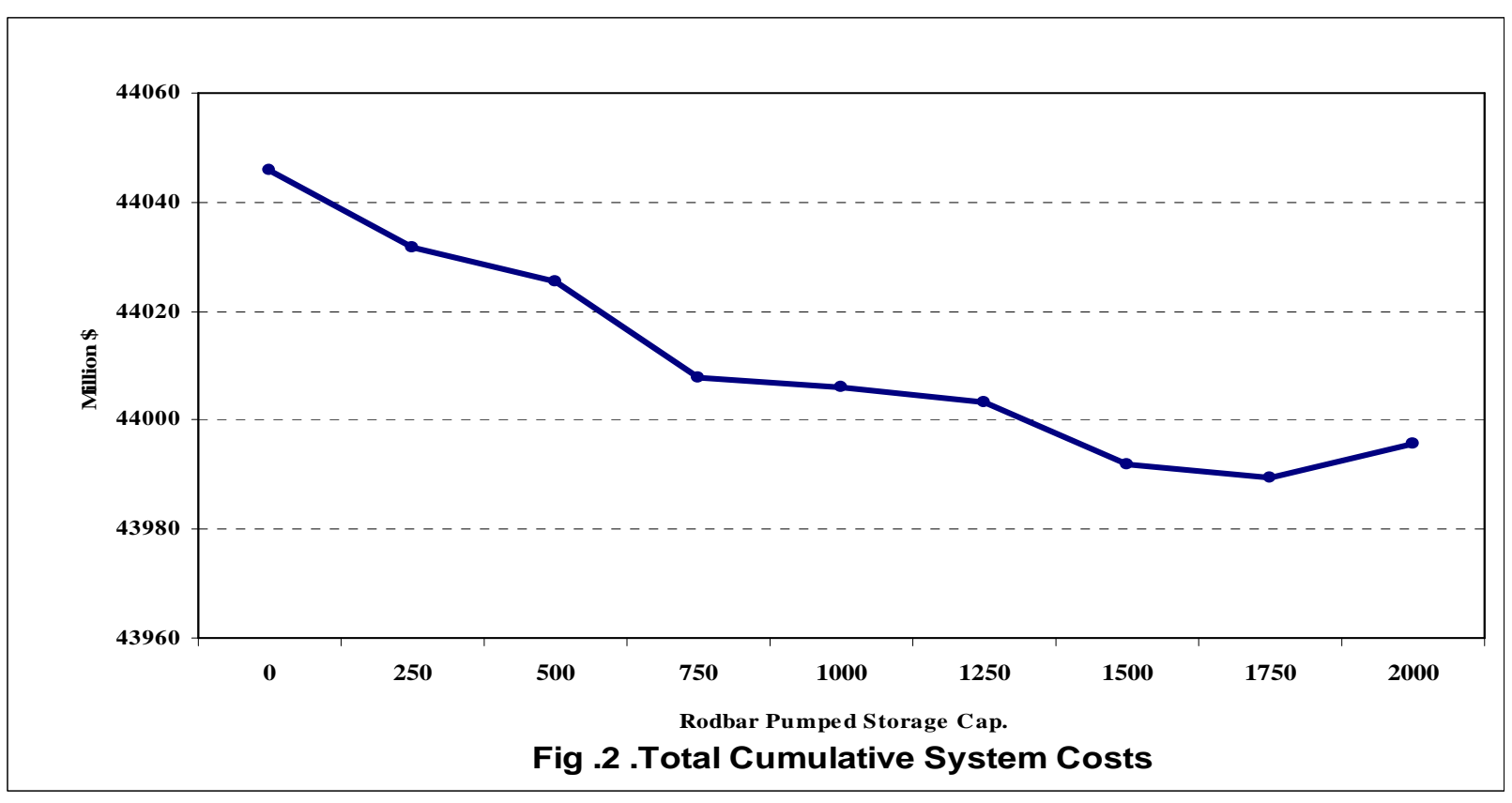

